\title{
Analysis of thermodynamic parameters in spark ignition VCR engine
}

\author{
Patryk Urbański ${ }^{1, *}$, Maciej Bajerlein ${ }^{2}$, Jerzy Merkisz $^{2}$, Andrzej Ziółkowski ${ }^{2}$, and Dawid Gallas ${ }^{1}$ \\ ${ }^{1}$ Lukasiewicz Research Network - Rail Vehicles Institute "TABOR”, Warszawska 181, 61-055 Poznan, Poland \\ ${ }^{2}$ Poznan University of Technology, Institute of Combustion Engines and Transport, Piotrowo 3, 60-695 Poznan, Poland
}

\begin{abstract}
D models of Szymkowiak and conventional engines were created in the Solidworks program. During the motion analysis, the characteristics of the piston path were analyzed for the two considered engine units. The imported file with the generated piston routes was used in the AVL Fire program, which simulated combustion processes in the two engines with identical initial conditions. The configurations for two different compression ratios were taken into account. The basic thermodynamic parameters occurring during the combustion process in internal combustion engines were analyzed.
\end{abstract}

\section{Introduction}

Technological progress over the decades has enabled the engineers to move from the level of general efficiency of several percent in the case of steam engines up to over $45 \%$ in the most efficient internal combustion engines. Despite the huge success of such a large efficiency improvement, half of the fuel energy is still not converted into useful energy mostly due to thermal and mechanical losses.

One of the most important parameters of a reciprocating internal combustion engine, which affects the efficiency of the unit is the compression ratio $\varepsilon$. This parameter is the ratio of the maximum cylinder volume $\mathrm{V}_{\max }$ when the piston is in the $\mathrm{BDC}$ to the volume of the combustion chamber when the piston is in TDC, so when the volume of the chamber is the smallest $\mathrm{V}_{\min }[1,2]$. The internal combustion engine does not typically operate under stable conditions. This means that it often works in suboptimal conditions, where the constant value of the geometric compression ratio as a parameter is not the optimal solution, due to the resulting decrease in the overall efficiency of the system. Increasing $\varepsilon$ brings with it a visible improvement in engine efficiency and power, by increasing the pressure inside the combustion chamber. Increasing the described parameter value is, however, only profitable up to a certain point due to the increased resistance during the compression stroke and the probability of knock during combustion, which may lead to engine damage.

The use of a variable compression ratio may prove to be a solution to the above problem $[3,4]$. It is a type of a mechanism where it is possible to change the compression ratio during the engine operation, thus adjusting the engine operating parameters to the given operating conditions present at the time. The advantages of a system using this solution also include: the possibility of using alternative fuels and low-temperature combustion processes.

Ongoing research and development works seem to confirm the perceived potential of such a solution. The engine with this system will have a greater degree of complexity, however, the prospects of increased efficiency, reduced fuel consumption and reduction of exhaust emissions [5-8] make further research in this field necessary.

\section{Test objects}

Constructor Msc. Mirosław Szymkowiak designed a piston engine with an unprecedented crank and piston system (figure 1). The unit converts the reciprocating motion of the piston into the rotary motion of the crankshaft using a unique and innovative system. The energy coming from the piston motion is transferred to the swingarm by means of the first connecting rod. Then, through the swingarm and the second connecting rod, it is transmitted to the crankshaft. The swingarm is also mounted to pivot on the camshaft. Thanks to this last element, it becomes possible to adjust the compression ratio smoothly during operation simply by rotating it.

The engine has the shape of a cube with a side of 600 $\mathrm{mm}$. The eight-cylinder engine was designed in a tworow system (4 cylinders in a row). The main advantages of the engine are its reduced height by placing the crankshaft between the rows of cylinders. The variable compression ratio also allows the engine to be adapted to run on various fuels with a wide range of characteristics. The crank-piston system used in the engine also caused a reduction of the normal force acting on the cylinder barrel, which translates into a reduction in mechanical losses and an increase in the service life of the ringcylinder pair. Thanks to the described advantages, this

Corresponding author: patryk.urbanski@tabor.com.pl 
engine can be used in various types of vehicles [8] and industry.

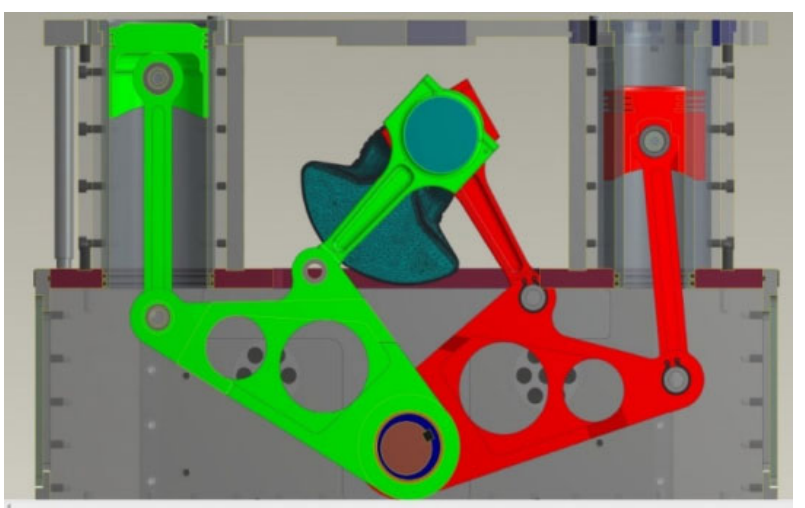

Fig. 1. Szymkowiak (or swingarm) engine design principle

For the purpose of simulating the combustion processes of the swingarm and conventional engines and their subsequent comparison, in 3D - Solidworks models of both units were created that represent their real geometrical dimensions. Based on the created models in the - motion analysis - tab the piston motion paths were generated (Figure 2) for each of the engines. The obtained piston motion characteristics were saved in a .txt file for use in combustion simulation.

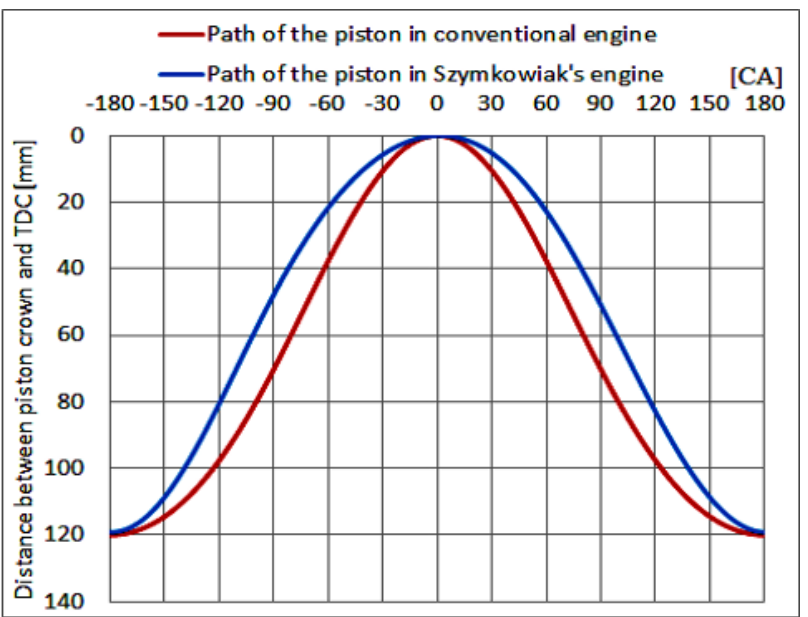

Fig. 2. Paths of motion for pistons in conventional and Szymkowiak's engines

\section{Combustion process simulation}

The AVL Fire program was used to simulate the combustion process. One of the program segments is the Workflow Manager tab. Using to this program it is possible to simulate processes of compression and spark ignition engines. This version of the program made it possible to simulate combustion processes in a sparkignition engine for conventional and Szymkowiak engines.

Based on the available data, a movable mesh of the combustion chamber was created. The combustion chamber shape was adopted as a cylinder, which means that the piston used had a flat bottom. The height of the cylinder was selected in such a way that the compression ratio was equal to 8.6 and 11.6. With these configurations, the cylinder motion path of an actual swingarm engine maintains symmetry with respect to the line passing through the TDC point. An important assumption of the simulation is the lack of fuel exchange. The considered range of motion of the piston was determined at $540-800{ }^{\circ} \mathrm{CA}$, which includes the compression stroke and the most important stage of the combustion stroke. The engine speed was set at $2000 \mathrm{rpm}$. The most important initial conditions for the simulation are presented in Table 1.

Table 1. Boundary conditions in simulations

\begin{tabular}{|c|c|c|}
\hline Parameter & Value & Unit \\
\hline \multicolumn{3}{|c|}{ Fresh air injected } \\
\hline Pressure & 97000 & $\mathrm{~Pa}$ \\
\hline Air density & {$[-]$} & $\mathrm{kg} / \mathrm{m}^{3}$ \\
\hline Temperature & 340 & $\bar{K}$ \\
\hline Turbulent kinetic energy & 11 & $\mathrm{~m}^{2} / \mathrm{s}^{2}$ \\
\hline Turbulent scale length & 0.003 & $\mathrm{~m}$ \\
\hline Initialization & Swirl/Tumble & {$[-]$} \\
\hline Turbulence velocity & 3000 & rpm \\
\hline $\begin{array}{l}\text { Direction of the axis of } \\
\text { turbulence rotation }\end{array}$ & $\begin{array}{l}X=0 \\
Y=0 \\
Z=1\end{array}$ & {$[-]$} \\
\hline \multicolumn{3}{|c|}{ Exhaust recirculation } \\
\hline Fuel type & Gasoline & {$[-]$} \\
\hline EGR mass fraction & 0.12 & {$[-]$} \\
\hline EGR composition & 0.478 & {$[-]$} \\
\hline Laminar flame velocity & Default & {$[-]$} \\
\hline
\end{tabular}

The program has several combustion models. The Extended Coherent Flame Model (ECFM) with a spherical shape of the initial flame nucleus was chosen for the computational needs of the simulation. The ECFM model is the manufacturer's recommended AVL program for simulating combustion in a spark-ignition engine [10].

Due to the use of gasoline as a fuel, it was necessary to determine the parameters related to the injection and ignition of the fuel-air mixture (Table 2). The direct fuel injection model was chosen. The injector has been positioned along the cylinder axis. The nozzle tip has been set at a distance of $2 \mathrm{~mm}$ from the engine head $(\mathrm{z}$ axis). The injection was assumed to take place at 660 ${ }^{\circ} \mathrm{CA}$. Due to the change in the compression ratio, the volume of the chamber varies depending on the setting of the camshaft and hence the air mass is also different. For this reason, in order to obtain a stoichiometric mixture, the mass of injected fuel will vary depending on the tested configuration. In the case of $\varepsilon=8.6$ the fuel weight for a single injection was $46 \mathrm{mg}$, and for $\varepsilon=11.6$ it was $43.5 \mathrm{mg}$.

The spark plug was set at a distance of $10 \mathrm{~mm}$ from the injector relative to the $\mathrm{y}$ axis and at a distance of $7 \mathrm{~mm}$ from the head ( $\mathrm{z}$ axis). The injector and the spark 
plug lie on the common $y-z$ plane. The ignition spark was determined to occur at $680{ }^{\circ} \mathrm{CA}$.

Table 2. Ignition and injection parameters

\begin{tabular}{|l|c|c|}
\hline \multicolumn{1}{|c|}{ Parameter } & Value & Unit \\
\hline \multicolumn{2}{|c|}{ Ignition parameters } & CA \\
\hline Spark timing & 680 & \\
Spark location & $\mathrm{X}=0$ & $\mathrm{~mm}$ \\
& $\mathrm{Y}=10$ & \\
\hline \multicolumn{2}{|c|}{ Injection parameters } & $\mathrm{CA}$ \\
\hline Injection timing & 660 & {$[-]$} \\
\hline Number of nozzle holes & $\mathrm{X}=0$ & \\
\hline & $\mathrm{Y}=0$ & $\mathrm{~mm}$ \\
Nozzle position & $\mathrm{Z}=2$ (from the engine head) & \\
\hline Mass of injected fuel & $46 ; \varepsilon=8.6$ & $\mathrm{mg}$ \\
\hline Fuel temperature & $43.5 ; \varepsilon=11.6$ & $\mathrm{~K}$ \\
\hline Outer diameter & 330.15 & $\mathrm{~mm}$ \\
\hline Inner diameter & 3.5 & $\mathrm{~mm}$ \\
\hline Half outer cone & 3.2 & $\mathrm{deg}$ \\
\hline Half inner cone & 48 & $\mathrm{deg}$ \\
\hline
\end{tabular}

The injection took place using a pintle nozzle type injector [11]. This is a single-hole injector designed for direct, high-pressure gasoline injection. Dimensions describing this element can be found in Table 2 and Figure 3 .

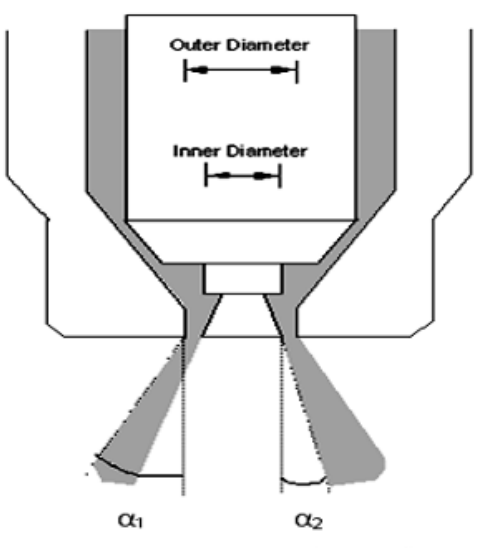

Spray Cone Angle $\left(\alpha_{1}, \alpha_{2}\right)$

Fig. 3. Diameters of the injector used [11]

The injection process is described by the Injection Rate Diagram (Figure 4). The injection time in the graph is a reference to the actual injection duration, which in the simulation was assumed to last a total of $0.3 \mathrm{~ms}$. Injection Rate has been selected to simplify the simulation and comparison with the real engine. At a later stage of research, it is planned to compare the simulation results with the actual performance of Szymkowiak's engine. For this reason, the simplification of the Injection Rate is a great help when controlling the injection in a real engine.

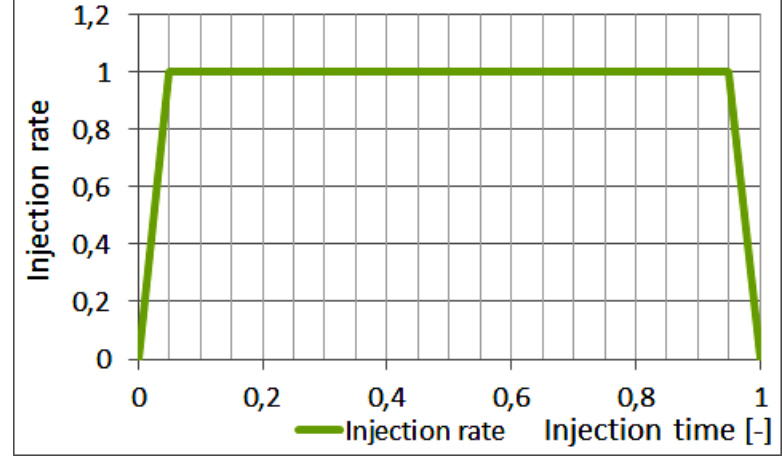

Fig. 4. Injection rate diagram

\section{Simulation results}

Simulations of engine processes were carried out for two Szymkowiak engine configurations. The first simulation was carried out for a compression ratio of 8.6, the second for a compression ratio of 11.6. At such camshaft settings, the piston motion path in the swingarm engine is characterized by symmetry with respect to the line passing the TDC. For comparative purposes, another combustion simulation was also carried out for a conventional engine with identical compression ratios. All initial conditions in the four performed simulations were identical. The exception was the mass of injected fuel, selected individually based on the value of the compression ratio. The subject of the analysis were: characteristics of the Equivalence Ratio distribution, pressure, temperature, rate of fuel evaporation and the heat recovery rate $[12,13]$.

\subsection{Compression ratio $=8.6$}

The parameter $\lambda$ describes the actual Air to Fuel Ratio (AFR) divided by the air-fuel stoichiometric ratio $\mathrm{AFR}_{\text {stoich }}(1)$. The equivalence ratio is in turn the inverse of the $\lambda(2)$ parameter.

$$
\begin{gathered}
\lambda=\frac{A F R}{A F R_{\text {stoich }}} \\
\text { EquivalenceRatio }=\frac{1}{\lambda}
\end{gathered}
$$

This parameter describes the flow behavior of the fuel stream in the AVL Fire program. The cross-section of the cylinder runs through its center and is visible in the $y-z$ plane. The cross-sections shown (Table 3 ) give the Equivalence Ratio at points 10, 20 and $30{ }^{\circ} \mathrm{CA}$ after injection. For comparative purposes, cross-sections from simulation of conventional and Szymkowiak engines were compiled.

There is a difference in the chamber height in individual engines for the cross-sections shown. Due to the characteristics of the piston path, the volume in each analyzed cross section will be smaller in Szymkowiak's engine. This has an impact on the air/fuel mixture combustion process quality. In the last tested point in the conventional engine, the fuel stream does not touch any 
of the walls. On the other hand, in Szymkowiak's engine, the fuel comes into contact with the piston's bottom, which may cause fuel deposition on the surface.

Table 3. Equivalence ratio in cylinder for $\varepsilon=8.6$. $\mathrm{C}$ - Conventional engine, $\mathrm{S}$ - Szymkowiak engine

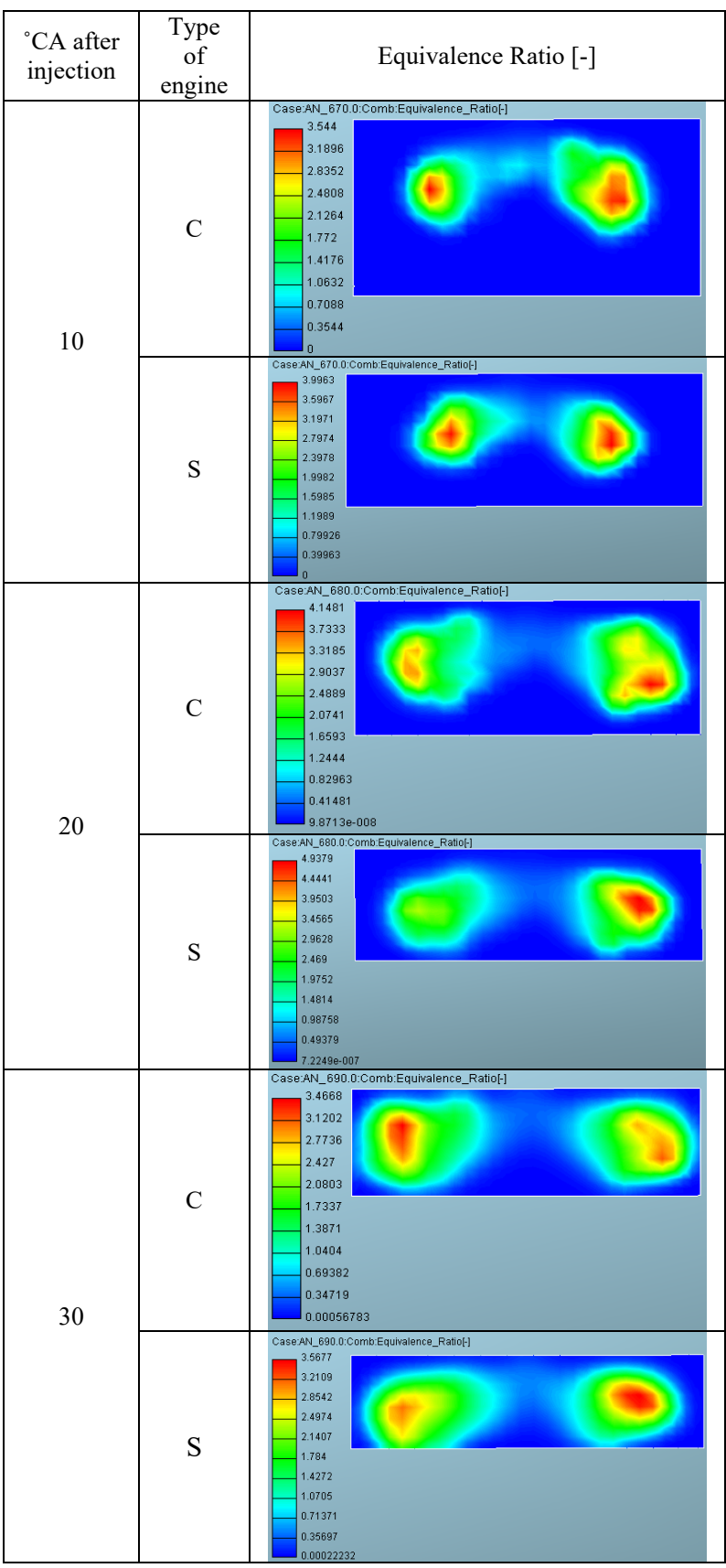

The distribution of mean cylinder pressure for simulations with a compression ratio 8.6 is shown in Figure 5. It is evident that the pressure in the swingarm engine has higher values in the wider $\mathrm{CA}$ range. The maximum value of the described parameter was 62.4 bar for Szymkowik's engine and was observed at $727.8^{\circ} \mathrm{CA}$. In the case of a conventional engine, the highest pressure value reached the level of $62.5 \mathrm{bar}$, which was found at $727.2{ }^{\circ} \mathrm{CA}$. The points of reaching the maximum pressure are practically identical.

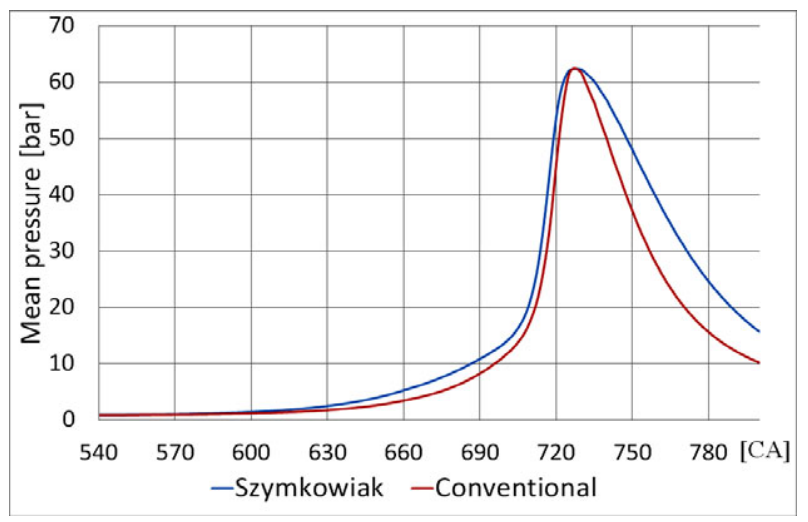

Fig. 5. Mean pressure in cylinder for $\varepsilon=8.6$

The temperature distribution characteristic is shown in Figure 6. In the compression stroke in Szymkowiak's engine, this parameter value is higher than for the conventional unit, which is due to the piston path characteristics, in which the compression element is located closer to the TDC at the same CA. The maximum values achieved in the simulation are 2374.19 $\mathrm{K}$ in the range of $736.6-736.9{ }^{\circ} \mathrm{CA}$ in the case of a swingarm engine and $2449.49 \mathrm{~K}$ in $730.6{ }^{\circ} \mathrm{CA}$ for a conventional engine.

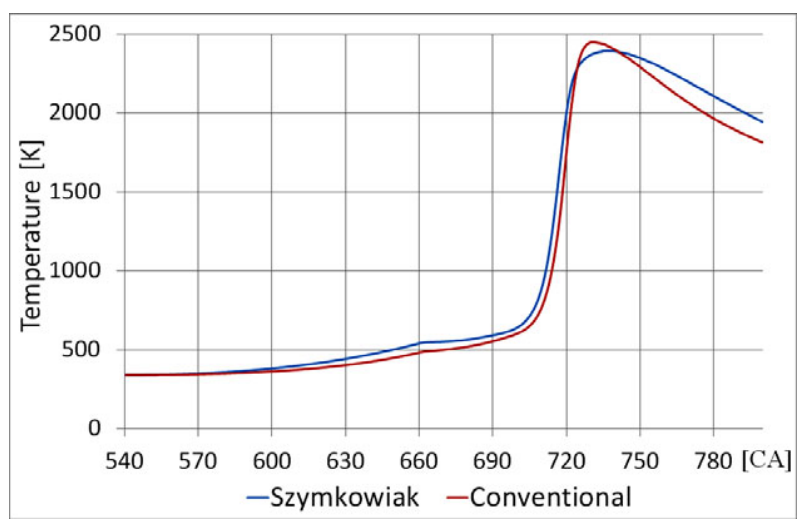

Fig. 6. Mean temperature in cylinder for $\varepsilon=8.6$

Due to the different characteristics of the piston path in both engines, the temperature value has a significant effect on the evaporation rate of the injected fuel (Figure 7). The higher temperature in the compression stroke causes the gasoline to evaporate faster in Szymkowiak's engine. The duration of the process from the moment of injection to complete fuel evaporation was $34.5{ }^{\circ} \mathrm{CA}$ in Szymkowiak's engine and $58.1{ }^{\circ} \mathrm{CA}$ in a conventional engine. The moment at which $50 \%$ of the fuel evaporated was at $672{ }^{\circ} \mathrm{CA}$ and $674{ }^{\circ} \mathrm{CA}$ in the swingarm and conventional engine.

The heat release rate (Figure 8) in Szymkowiak's engine reached the maximum value of $107.83 \mathrm{~J} / \mathrm{deg}$ at $717.2{ }^{\circ} \mathrm{CA}$. In the case of a conventional engine, this value was $127.69 \mathrm{~J} / \mathrm{deg}$ and was reached at $719.8{ }^{\circ} \mathrm{CA}$. This means that the value obtained in the conventional engine is $18.4 \%$ higher than for the swingarm engine. Heat dissipation is more distributed over time in the case of the swingarm engine. A measure of the fuel energy use is the Accumulated heat release (Figure 9), which is a sum of the heat produced. For Szymkowiak's engine, 
the result was $1615.76 \mathrm{~J}$ while for the conventional engine it was 1681.13. This indicates a better use of fuel energy by $4 \%$ in the conventional engine.

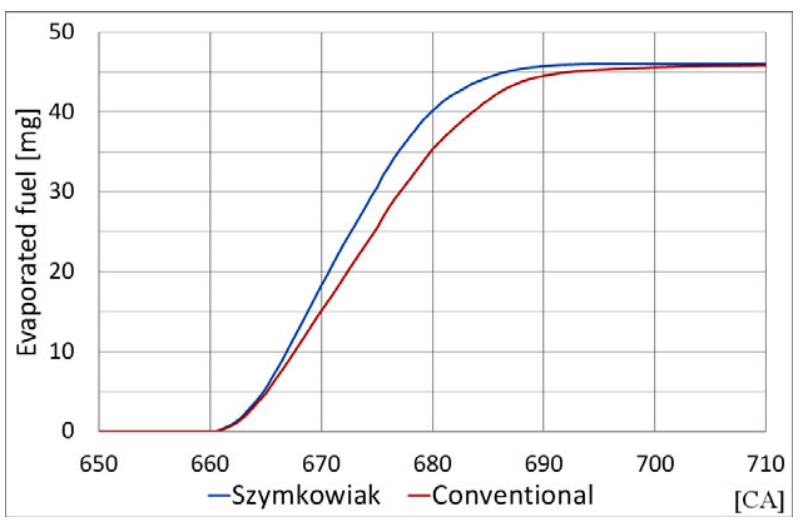

Fig. 7. Evaporation of injected fuel for $\varepsilon=8.6$

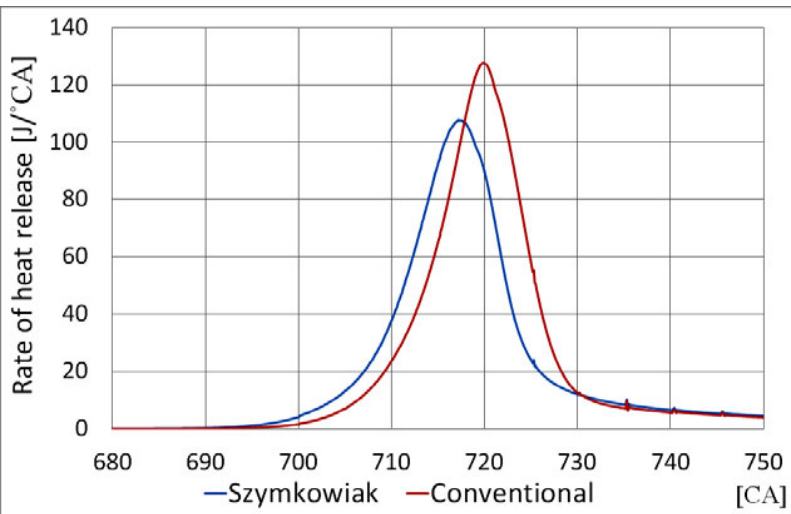

Fig. 8. Rate of heat release for $\varepsilon=8.6$

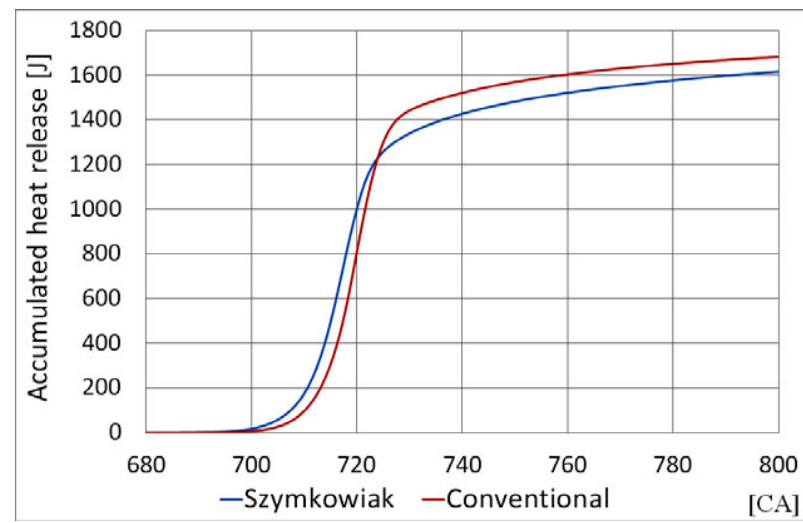

Fig. 9. Accumulated heat release for $\varepsilon=8.6$

\subsection{Compression ratio $=11.6$}

The equivalence ratio for the compression ratio equal to 11.6 is shown in Table 4. It is clear that the shape and area of the Fuel Spray section is visibly different depending on the engine type. When increasing the compression ratio, the height of the chamber decreases at the same time, which translates into a smaller cylinder volume. In addition, in Szymkowiak's engine, the height will be smaller relative to the conventional engine due to the characteristics of the piston motion path. This factor contributes to the dispersion of the fuel mist in the cylinder. As can be seen at $30^{\circ} \mathrm{CA}$ after injection in both engines there was a fuel contact with the surface of the combustion chamber. In Szymkowiak's engine, however, the contact surface is significantly larger, which indicates a lower combustion quality.

Table 4. Equivalence ratio in cylinder for $\varepsilon=11.6$.

$\mathrm{C}$ - Conventional engine, $\mathrm{S}$ - Szymkowiak engine

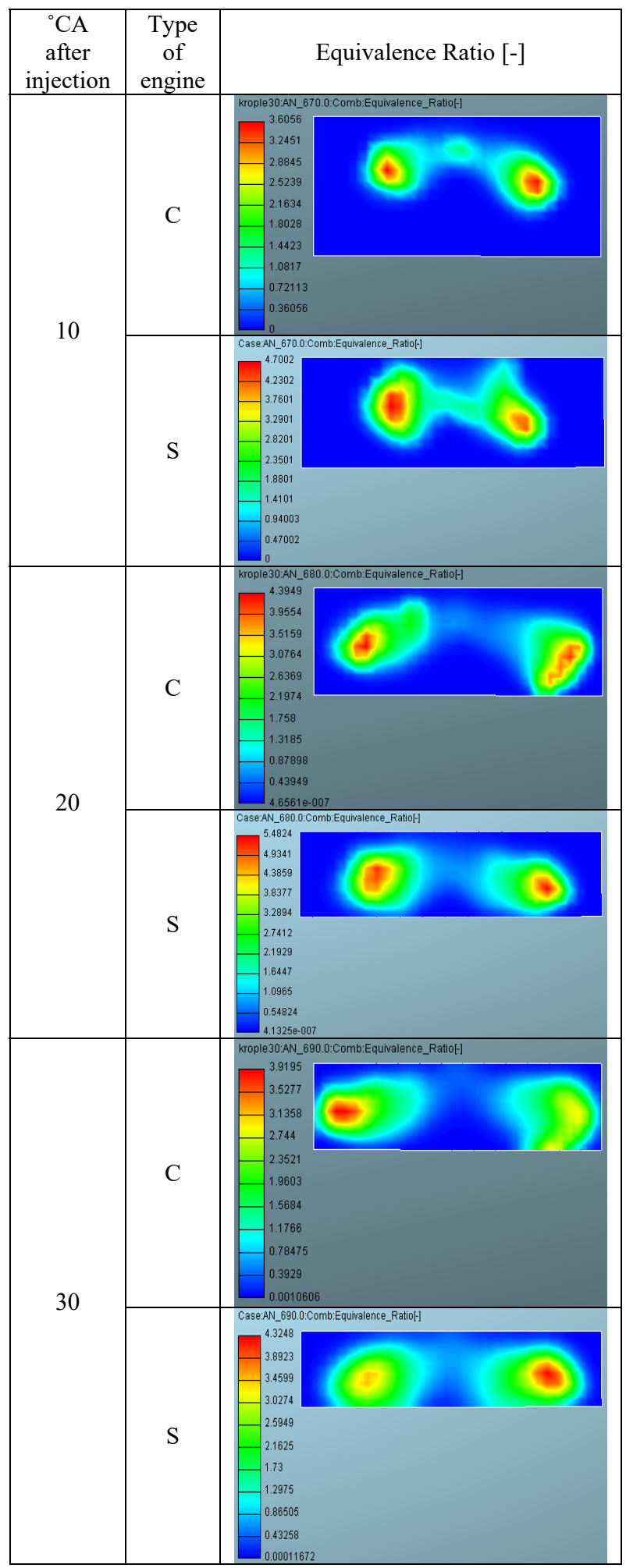

In simulations for the compression ratio of 11.6 , the distribution of mean cylinder pressure is shown in Figure 10. In Szymkowiak's engine the pressure has a clearly 
wider range of high values which can have a positive effect on the torque distribution. The maximum of the described parameter is reached at $4.8{ }^{\circ} \mathrm{CA}$ after TDC in both engines. The values of the generated pressures, however, differ. In Szymkowiak's engine, the maximum pressure was 86.1 bar, while in the conventional engine as much as $90 \mathrm{bar}$.

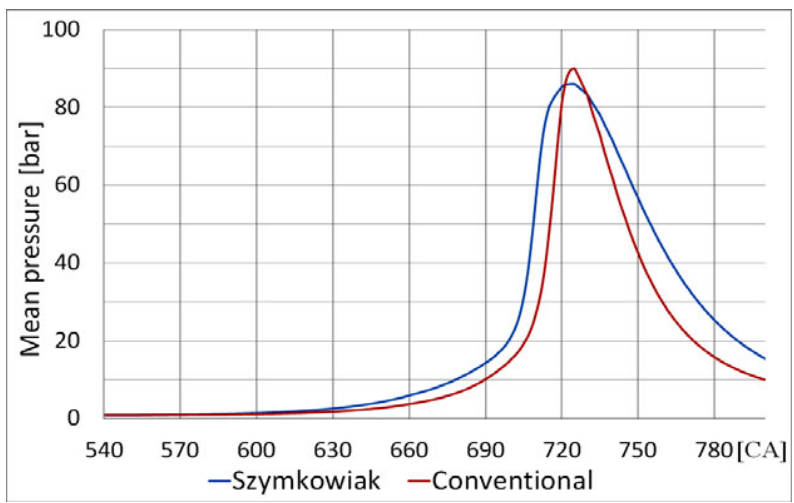

Fig. 10. Mean pressure in cylinder for $\varepsilon=11.6$

The average temperature prevailing in the cylinder (Figure 11) as in the case of $\varepsilon=8.6$ is higher in the compression stroke in the VCR engine. After exceeding $680{ }^{\circ} \mathrm{CA}$, at which point the ignition occurred, the temperature in the initial phase of the combustion process is also higher in the swingarm engine. The reason is the accelerated heat release rate (Figure 13) which indicates a faster combustion process. The maximum temperature reached was $2349.6 \mathrm{~K}$ at $730{ }^{\circ} \mathrm{CA}$ in the case of Szymkowiak's engine and $2537.8 \mathrm{~K}$ at $726.3{ }^{\circ} \mathrm{CA}$ in a conventional engine. The difference was about $7.5 \%$ which means that the probability of nitrogen oxides formation in a conventional engine is much higher.

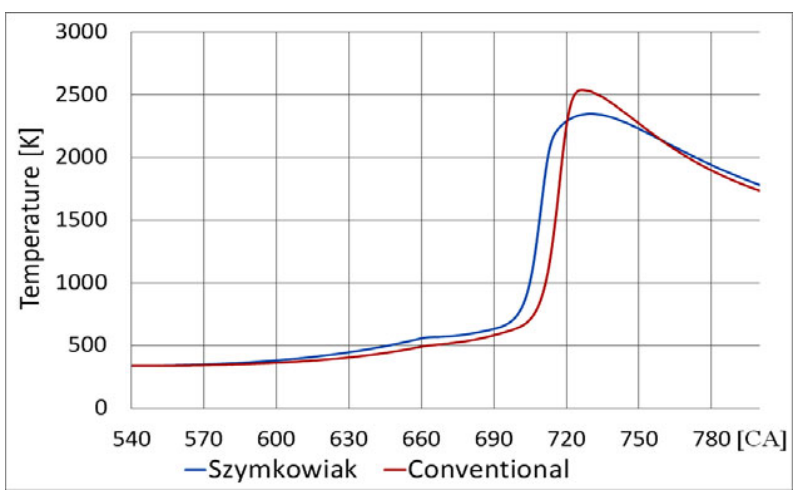

Fig. 11. Mean temperature in cylinder for $\varepsilon=11.6$

Evaporation of fuel for the compression ratio of 11.6 (Figure 13) also took less time in the case of Szymkowiak's engine $-32.5{ }^{\circ} \mathrm{CA}$. The conventional engine process lasted $6.5{ }^{\circ} \mathrm{CA}$ longer. Increasing the compression ratio resulted in shortening the duration of fuel evaporation by $2{ }^{\circ} \mathrm{CA}$ in Szymkowiak's engine and by $19.1{ }^{\circ} \mathrm{CA}$ in the conventional one. The time required for evaporation of half the fuel mass was equal to 11 ${ }^{\circ} \mathrm{CA}$ in the VCR engine and $14{ }^{\circ} \mathrm{CA}$ in the conventional engine.

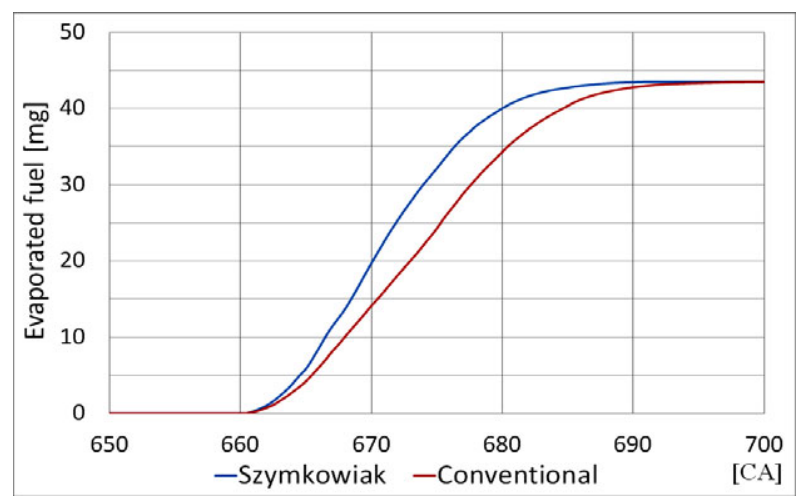

Fig. 12. Evaporation of injected fuel for $\varepsilon=11.6$

The heat release rate for $\varepsilon=11.6$ is shown in Figure 13. The graph shows that the combustion process took place faster in Szymkowiak's engine. The peak for the VCR unit was at $10{ }^{\circ} \mathrm{CA}$ before TDC and was 115.1 $\mathrm{J} / \mathrm{deg}$. In a conventional engine, the maximum achieved value is 24.3 units higher than for the swingarm engine and takes place at $2.6{ }^{\circ} \mathrm{CA}$ before TDC. The difference between the maximum values reaches $21 \%$.

Accumulated Heat Release (fig. 14) for the conventional engine reached the final value of $1650.6 \mathrm{~J}$. This result is $178.5 \mathrm{~J}$ greater than in the case of Szymkowiak's engine. The difference in the use of fuel energy at the level of $12 \%$ results in a significant reduction in the overall efficiency, remembering that this parameter is a product of several component efficiencies, including the thermal efficiency of the engine.

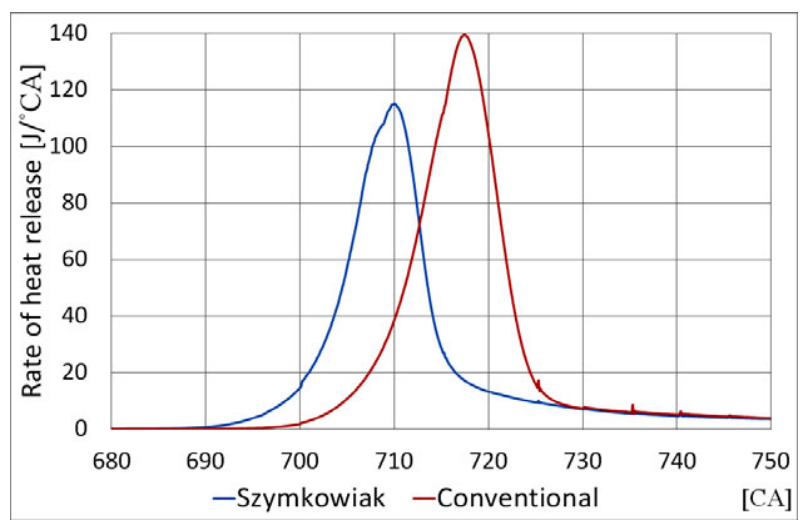

Fig. 13. Rate of heat release for $\varepsilon=11.6$

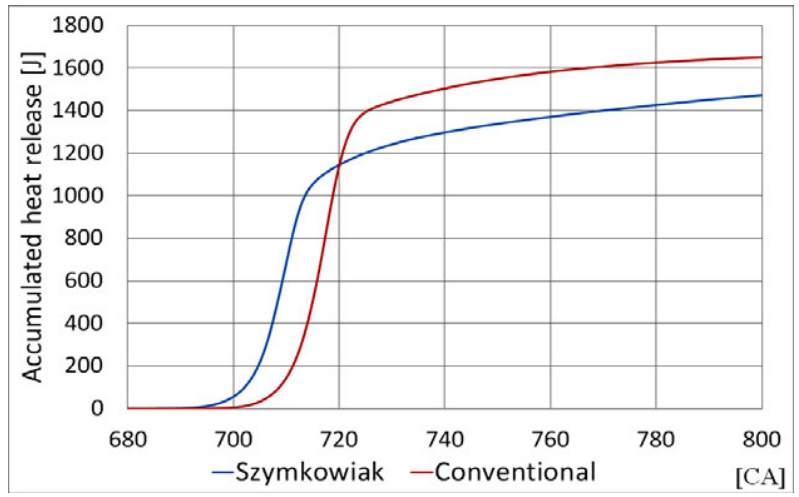

Fig. 14. Accumulated heat release for $\varepsilon=11.6$ 


\section{Conclusions}

The conducted simulations were aimed at the analysis and comparison of the thermodynamic processes taking place in Szymkowiak's and conventional engines. With the identical boundary conditions and the same moment of fuel injection for which the crankshaft position was the determinant, the most important conclusions drawn from the simulation are:

- The characteristics of the piston motion path has a significant impact on the Fuel Spray distribution in engines. In the Szymkowiak engine, due to the smaller volume of the combustion chamber, the probability of contact between the fuel spray and the elements forming the chamber is higher.

- The maximum pressure values obtained in simulations are quite similar to each other. The points at which these values were reached were also very similar. An interesting aspect is the cylinder pressure characteristics. In Szymkowiak's engine, the range of higher pressure values is wider. This means that despite the achievement of lower maximum values compared to a conventional engine, a wider range of higher pressure can translate into higher values of average useful pressure and, consequently, a better distribution of torque.

- Lower maximum temperatures in Szymkowiak's engine mean that the risk of nitrogen oxides being formed is significantly lower.

- The fuel evaporation rate for both tested compression ratio values is greater for Szymkowiak's engine. This means that the preparation of the fuel-air mixture will be faster in the swingarm engine.

- The maximum values and the location where heat is released were visibly different. The combustion process is faster in Szymkowiak's engine and it is more evenly spread over time. Accumulated heat release proves that in Szymkowiak's engine the use of fuel energy is slightly worse. This is the effect of the contact of the fuel stream with the walls of the combustion chamber.

- The assumed identical fuel injection timing for both engines, determined based on the crankshaft angle, is not optimal for Szymkowiak's engine due to the smaller volume of the combustion chamber and, as a consequence, worse conditions of the fuel stream propagation. For this reason, plans were made to perform simulations for fuel injection where the timing is determined based on the distance of the piston from TDC.

- Plans have also been made to compare the obtained simulation results to the results from a real engine. Such analysis will be aimed at verifying the accuracy and legitimacy of using a combustion processes simulation instead of real engine tests.

\section{References}

1. J. Heywood, Internal Combustion Engine Fundamentals. McGraw-Hill Education (2018)

2. T. Hoeltgebaum, R. Simoni, D. Martins, Elsevier, 96, 308-322 (2016)

3. A. Shaik, N. Moorthi, R. Rudramoorthy, Professional Engineering Publishing LTD, 221, 1159-1168 (2007)

4. S. Nagarajaa, K. Sooryaprakashb, R. Sudhakaran, Book Series: Procedia Earth and Planetary Science, 11, 393-401 (2015)

5. P. Daszkiewicz, M. Andrzejewski, MATEC Web of Conferences, 118 (2017)

6. L. Rymaniak, MATEC Web of Conferences, 118, (2017)

7. K. Andrzejczak, J. Selech, TRANSPORT PROBLEMS, 12, 103-111 (2017)

8. M. Andrzejewski, D. Gallas, P. Daszkiewicz, A. Merkisz-Guranowska, H. Stawecka, MATEC Web of Conferences, 118 (2017)

9. L. Rymaniak, P. Daszkiewicz, J. Merkisz, Y.V. Bolzhelarskyi, AIP Conference Proceedings, 2078 (2019)

10. AVL Fire ${ }^{\mathrm{TM}}$ Version 2017 - Combustion Module

11. AVL Fire ${ }^{\mathrm{TM}}$ Version 2017 - Spray Module

12. I. Pielecha, 222, 64-73, (2018)

13. I. Pielecha, W. Cieslik, JOURNAL OF THERMAL ANALYSIS AND CALORIMETRY, 126, 815-827 (2016) 